\title{
Taking Care of the Symbolic Order. How Converging Technologies Challenge our Concepts
}

\author{
Tsjalling Swierstra $\cdot$ Rinie van Est • \\ Marianne Boenink
}

Received: 5 November 2009 / Accepted: 5 November 2009 /Published online: 3 December 2009

(C) The Author(s) 2009. This article is published with open access at Springerlink.com

\begin{abstract}
In this article we briefly summarize how converging technologies challenge elements of the existing symbolic order, as shown in the contributions to this special issue. We then identify the vision of 'life as a do it yourself kit' as a common denominator in the various forms of convergence and proceed to show how this vision provokes unrest and debate about existing moral frameworks and taboos. We conclude that, just as the problems of the industrial revolution sparked off the now broadly established ideal of sustainability the converging technologies should be governed by the ideal of 'human sustainability'. The essence of this ideal is formed by the ongoing discussion about the extent to which we may, or should want to, 'make' our environment and ourselves, and when it is better to simply accept what is given and what happens to us.
\end{abstract}

Keywords Converging technologies $\cdot$ Ethics

Sustainability

T. Swierstra $(\bowtie) \cdot$ M. Boenink

Faculty of Behavioural Sciences,

Department of Philosophy, University of Twente, P.O.Box 217, 7500 AE Enschede, The Netherlands e-mail: t.e.swierstra@utwente.nl

R. van Est

Rathenau Institute,

P.O.Box 95366, 2509 CJ Den Haag, The Netherlands

\section{Introduction}

Stimulation of parts of one's brain so that one's behaviour 'fits in' better, a material environment that helps one conquer weakness of will, permanent remote monitoring to guard one's health and the design and building of new forms of cellular life. This is only a small selection from the preceding articles to illustrate the varied nature of what is in store for us if nanotechnology, biotechnology, information technology and cognitive science (NBIC) converge with one another.

It is not clear what will actually become possible within the foreseeable future and what will remain figments of our imagination [19, 20]. Nevertheless, we must not consider the promise of converging technologies as empty right from the start. Promises and expectations have an effect, whether they are realistic or not. They shape our contemporary research agenda and, in doing so, the future [2]. It is important that we examine whether the perspective they offer is attractive or not. This normative question is, however, just as difficult to answer. Converging technologies are causing uncertainty as regards the area of norms and values too [9, 15]. To what extent can we, for instance, still hold people responsible if our free will can be dismissed as an illusion generated by our brains? (See Schermer, this 
issue.) If intelligent devices partially take over the function of our consciences, does that mean that a part of our moral liability will also be delegated? (See Verbeek, this issue.) Is a transparent body indeed as desirable as many now think or, in 15 years' time, shall we long for the time that we were not constantly being confronted with our bodies? (See Boenink, this issue.) And must patent legislation, once thought up for totally different matters, be amended in the light of developments in synthetic biology? (See Van den Belt, this issue.) New problems require new solutions. Some parts of our current ethical, legal and political convictions and institutions will, therefore, probably evolve along with science and technology. But how and in what direction? Uncertainty reigns in the normative area as well.

As the foregoing articles have exhaustively illustrated, in the case of NBIC convergence we are dealing with a third level of uncertainty. The symbolic order [6], the stock of twin concepts we use to categorize our reality, faces numerous challenges from scientific and technological developments. The distinctions between human and machine, body and mind, sick and well, freedom and responsibility, organic life and inorganic matter are simply not as obvious as they used to be. This confusion, which is as fundamental as it is difficult to grasp, is working its way to the surface in concrete ethical questions and controversies. Technological innovations require the re-assessment of symbolic concepts. [25] Table 1 briefly summarizes how the forms of NBIC convergence handled earlier lead to the modification of the symbolic order.

This is why we discuss the character of the converging technologies and the fundamental challenge they present us with, generally speaking, in this concluding article.

In section two we identify a common denominator in the various forms of convergence that have been dealt with in the separate articles of this special issue. We argue that NBIC convergence is founded on an underlying vision in which life is visualized as a doit-yourself kit, and that convergence actively promotes this vision. This idea implies that we can also take the world apart and rebuild it to our own taste. Section three describes how this vision leads to unrest and debate about existing moral frameworks and taboos. Section four searches for a solution. Just as the problems of the industrial revolution sparked off the now broadly established ideal of sustainability in the past, the new technological wave should allow itself to be led by the ideal of 'human sustainability'. The essence of this ideal is formed by the ongoing discussion about the extent to which we may, or should want to, try to 'make' our environment and ourselves, and when it is better to simply accept what is given and what happens to us. Section five contains a short conclusion.

\section{Life as a do-it-yourself kit}

Although technological convergence can take place in extremely diverse fields and very different forms, two characteristics are generally evident. First, a process of computerization of reality always precedes convergence. In The Third Wave [27], Toffler distinguishes between three successive technological waves: the agricultural revolution, the industrial revolution and the information revolution. Because of the fundamental importance of the computerization of reality for NBIC convergence, there is something to be said for not calling this a separate new technological wave, but simply a new phase in the third technological wave. Second, there is also the matter of the sweeping miniaturization of devices that has been enabled by nanoscience and technology

The concrete effects of computerization and miniaturization can vary enormously, as the previous articles have shown. Nonetheless, a common denominator can be found in this diversity: the convergence of technologies is generally inspired by the hope of increasing the 'makeability' of the organic world and of life itself [14, 22]. This may not seem very shocking on the face of it. After all, from the very beginning technology has focused on control and influence, on moulding reality to suit oneself. The intention of technology is to make reality makeable. That applied to the discovery of fire and the needle and thread, and that applies now, too, to synthetic organisms and to brain-computer interaction $[16,17,30]$.

NBIC convergence intends to make large parts of reality controllable. However, the articles in this special issue show that there is also a more fundamental, qualitative change involved. Converging technologies are founded on and complete a scientific 
and technological paradigm shift that gives rise to a philosophical paradigm shift. In order to make this clear, the general concept of 'technical makeability' has to be further analysed because, in fact, so far we have used this term for two fundamentally different types of 'making'.

\section{Building with Non-Living Matter}

The most literal use of the term 'making' is for the manipulation of lifeless matter. In this case, making means putting together the desired whole from separate materials and parts. For example, we first design a house and then we make it out of bricks, cement, wood, etc.; or we make a machine by arranging and connecting nuts, bolts, chips and what not into a functioning whole; or we make a garment by combining separate 'building blocks' such as fabric, thread and buttons with the aid of instruments (needle and scissors) in a certain way. All the materials we use to do so, including reinforced concrete, plastic and thread can, in turn, also be made by humans. This is making in the sense of building. We associate 'building' with the non-living, inorganic world.

\section{Influencing Living Matter}

We also re-make the world of organic, living nature with the aid of technology. In this way we hope to make nature serve our purpose. We have already been 'making' new grain varieties and chicken breeds for thousands of years. We keep people healthy by sharing the latest scientific insights on healthy living with them, or having them tested regularly for signs of illness. We make patients a bit better, or cure them altogether, by giving them medicine or equipping them with an artefact or prosthesis. We make a person morally better by educating him or her using pedagogic understanding. Every one of these cases involves

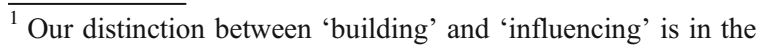
background inspired by Hanna Arendt's distinction between 'work' and 'action'. [1] With 'work' she refers to the activity of making objects, so it is more or less the same as technique or technology. With 'action' she refers to shared deliberation and acting. Action involves a relation between subjects. Our concept of 'building' is akin to her concept of 'work', but whereas Arendt restricts 'action' to inter-human relations, we extend it — rechristened as 'influencing' — to the relation between humans and live organisms in general.
}

technical makeability. After all, they are all interventions based on instrumental knowledge and/or the use of technical instruments.

Nevertheless, it is immediately clear that the breeding of plants and animals involves a totally different type of 'making' than when we build a house or machine. Plants and animals are neither designed nor built. When we try to heal or educate a person, we do not do so by building a better version. For these forms of making we do not, therefore, use the term 'building', but 'controlling (in the sense of steering)' or 'influencing'. We deem these latter concepts more appropriate in such cases. We build non-living matter; we influence organic life: microorganisms, plants, animals or humans.

\section{The Recalcitrance of Life}

The distinction between building and influencing is, of course, gradual, not binary. There lies a continuum of possibilities between the two. It is, however, not coincidental that 'building' has so far chiefly been associated with non-living and 'influencing' with living matter. In actual fact, living organisms have a particular way of resisting our attempts to subdue and transform them. 'Living' can be defined as the capacity to reproduce oneself. And that means that those wishing to make living organisms, will be competing with the organism itself. In such cases there are two creators at the helm. Living beings that become the object of control show a unique sort of recalcitrance: a bacterium can become resistant to antibiotics, animals that are bred for specific traits sometimes become more prone to illnesses, our children can dispute the correctness of our teachings. The actorship of the organism in question is recognized in the terms: influence and manipulation. Whereas we can, as a rule, bend a non-living thing to our will, we are far more likely to conclude a compromise with a living organism.

\section{Life as a do-it-yourself kit}

It is precisely this fundamental dividing line that is brought into focus and is problematized by converging technologies. For the first time it appears as though the organic world is becoming makeable in the sense that it can be designed and built [18]. The computerization and miniaturization which form the 
basis of converging technologies, undermine the significance of the distinction between non-living and living, between passive and active. Organisms are just as good carriers of information as software packages or chemical substances. And on the nanoscale, the whole thing is simply a matter of molecules and chemical compounds, so that it is meaningless to designate one molecular compound as 'living' and another as 'non-living'. As the Dutch professor of molecular biophysics, Cees Dekker, put it in connection with synthetic biology: "If you can produce an independent, reproducing being from non-living building blocks (DNA, proteins, lipids) you can make life. [...] Man has a certain control over both non-living and living nature. There is no fundamental difference between the two as far as I am concerned" [24]. Life is molecular activity. The symbolic boundary between non-living matter and living nature is blurring. Within this new paradigm, nature is approached as a machine: a moving whole, but composed of non-living parts.

We ourselves make up a prominent part of living nature. The promise of the industrial revolution was that all manner of processes would become more makeable (faster, more efficient, larger scale). Lifeless nature was increasingly seen as a collection of 'natural resources'. Iron and coal were typical raw materials for the industrial revolution. However, that changed with the emergence of converging technologies. Merelman ([18], p. 179) shows how the emphasis within science and technology gradually shifted from 'external' nature to 'internal' human nature: "Most important, the post-modern focus on human life merely extends the modernist attention to nature. Post-modern technological culture simply treats human beings as part of nature." Indeed, not only will it be possible to build or rebuild the world around us, but also ourselves. The central message behind converging technologies is therefore that it will, in time, be possible to build people themselves, as a part of our living nature.

In this way, our bodies, our brains and our social world form the new raw materials. Technologies such as genetics, neurology, pharmacology, medical technology and ICT mesh with our memory and our personality, with human reproduction and our physical performances. The distinction between body and mind is difficult to maintain in the light of recent scientific and technical insights: everything about living systems, ourselves included, is a product of the interaction between molecules. Robot expert
Rodney Brooks ([3], p. 107) of the Massachusetts Institute of Technology (MIT) brings this paradigm shift into focus as follows: "The generalization facing us is that we humans are machines, and as such, subject to the same manipulation that we routinely apply to machines." NBIC convergence enables the merging of artificial systems with our biological systems. In short, we have to do with a radical expansion of the building logic applied to non-living nature in the direction of living nature. Regarded in this way, transhuman enhancement is the culmination point of the transition from controlling to building that is being realized by converging technologies. If converging technologies live up to their promise, the resistance of living organisms will be broken. Even if this promise is exceptionally speculative, this analysis at least gives an indication of the visions that are currently serving as a guide for a lot of research and technical developments.

Will it be increasingly possible for people to unilaterally determine what in the past could only be realized by negotiation and compromise? The articles in this special issue give examples of such cases. Whereas the development of new medicines is now usually a matter of trial and error we will, if we are to believe what the molecular biologists tell us, in the near future be able to accurately determine what is happening in a sick cell and build an effective medicine for it with molecular technologies. The modification of micro-organisms currently takes place by smuggling a foreign gene in from the outside and hoping for the best. But the Craig Venter Institute is on the verge of building an artificial bacterium. This first artificial form of life created by man has already been nicknamed Synthia, as a humorous reference to Dolly, by the environmental organizations. The enhancement of plants and animals is still taking place by crossing, and then just hoping that something useful will be produced. In the long term we should, thanks to synthetic biology, be able to build plants and animals to order and according to a specific design. As a result of persuasive technology we will no longer have to trust to the power of weak arguments, or to our even weaker 'better self'; by means of a shortcut we will immediately be able to steer our behaviour effectively in the desired direction. And if persuasive technology fails after all, thanks to converging technologies we will be able to intervene directly in our brains to switch on or off the required connections. 
Living and Non-Living Nature

Converging technologies will enable us to realize existing objectives faster, more directly, effectively, easily, comprehensively and often more invisibly than previously possible. For the time being, however, they do not appear to differ all that much from the already established (social) technologies as regards effectiveness. Insisting that someone do something or imposing a fine on him or her, will frequently be at least as effective as an educational mirror or telephone. Controlling someone's behaviour by inserting electrodes in his or her brain will not always be more effective than giving them a pill. We do not have to have synthetic biology at our disposal to make sweeping modifications in living organisms to suit our economic requirements. And we do not have to discover implantable nanosensors to become healthobsessed hypochondriacs. In other words: as long as converging technologies are still in their infancy, 'building' may not always be more effective or more radical than 'controlling' or 'tinkering'.

However, this justifiable qualification does not alter the radical character of the paradigm shift we have spotted. Both forms of making — that is controlling versus building - imply a fundamentally different relationship between humans and reality. Thanks to converging technologies, a form of making that has so far remained restricted to our interventions in the domain of non-living nature, has now expanded to include the domain of living nature, ourselves included.

\section{Emerging Boundary Conflicts}

'Building' and 'controlling/steering' entail two fundamentally different relationships with reality. This difference can be seen as the difference between the objectifying and the social perspective on reality. If the boundary between these two perspectives can no longer be clearly drawn, this will lead to a great deal of moral uneasiness. There are two reasons for this.

\section{Conflicting Perspectives}

People apply two fundamentally different perspectives to outside reality $[10,26]$. On the basis of the objectifying perspective the world appears as a total of facts. We know, for example, that our partner consists of molecules and chemical processes, and we would like the doctor to see him or her like that too. In fact, this objectifying manner of looking at things leads to scientific knowledge and technical solutions - an effective medicine, for example. However, we have also learned that the scientific, objectifying view of the world is not a universal panacea. This is why we also apply a social perspective that sees the world as a whole comprising norms, values and meanings. As a rule, we naturally see our partner on the basis of this social perspective, and the doctor has to be able to do the same. We can view animals, and even plants, using this social perspective. The essence of this perspective is the abovementioned acknowledgement of the independent actorship of living organisms.

We are generally able to apply both perspectives side by side. In most situations we intuitively know the appropriate way to view things. And if not, there are strict rules and prohibitions, or taboos, to define a sharp boundary between the two perspectives. Kant's ban on viewing our fellow man purely as an instrument serves as a good example here [12]. Sometimes, however, there is no consensus as to whether the objectifying or the social view is preferable. This throws up social controversies that often go exceptionally deep and are correspondingly difficult to solve, such as the discussion on preimplantation genetic diagnostics. Are the embryos involved 'lumps of cells' or 'tiny people'? These two mutually exclusive ways of looking at things are ethically charged because they lay down those options that are morally acceptable and those that are not. If converging technologies now enable us to ignore the actorship of living organisms unpunished, the basic experience forming the reason for existence of the respect underlying the social perspective threatens to disappear. The taboos that currently still safeguard the boundary between the objectifying and the social perspectives will, as a result, be subjected to increasing pressure.

\section{Evaporating Taboos}

Let us give an example. Seen from the social perspective, one may only influence the opinions and behaviour of others by trying to persuade them of one's own way of thinking — out of respect for the other's autonomy. In the Netherlands as recently as the nineteen seventies, a criminologist called Buikhuisen was ostracized from the circle of right-minded, 
respectable citizens because he attempted to forge a connection between psychological traits and biological characteristics. After all, this smacked of racism or sexism: groups were stigmatized and social inequalities were justified with a reference to presupposed biological differences [5]. Nowadays, however, research of this type is again taking place — without opposition. Geneticists and cognitive scientists have already demonstrated that many of our traits and behaviours indeed have a genetic or biological component. In theory, through computerization and miniaturization, psychological traits are now also within reach of technological and biotechnological intervention. Scientists freely investigate how our thoughts and actions can be controlled by technology: directly by means of chemical or electronic methods, or indirectly with the aid of persuasive technology. Here we see how 'making' takes over from 'steering'. After all, such research assumes a way of looking at our process of weighing up a situation in which the definition or determinability of our thinking is central rather than our freedom, autonomy and rationality. We do not fully realize it, but an important taboo is being broken here. And in a sense, the step currently being taken is more radical than that of Buikhuisen. Whereas he was only interested in the criminal mind, these days it is all about 'building' everybody's mind.

The Norm of 'Naturalness': as Impossible as it is Inevitable

The makeability of life fascinates us, but it instantly arouses moral uneasiness and opposition at the same time. This not only has to do with the object of our aims, but also with our own situation as builders.

The fact that matters going in a certain way does not mean that they have to go that way was already brought to our attention more than four centuries ago. The Age of Reason sought its mission in conquering nature and we have all been more or less formed by that pursuit. It took the requisite time and secularization before the insight that nature is no longer the norm became widely accepted. Nature, as the adage has gone since then, does not contain any ethical behavioural instructions. According to science, the world as it is, including man himself, is not based on a plan, but is purely coincidental. Nothing is as it must be; in theory everything is capable of improvement. And we are still implementing that programme.
We therefore no longer live in a biotope, but in a technotope. Our world has been made by people and often that is a good thing too. Becoming sick is a very natural thing to do, but we still fight it tooth and nail.

And yet.... Nature, both external and internal, keeps cropping us as the norm. We want to live naturally, go back to nature, respect and conserve nature, deal naturally with one another, eat naturally and so on. The emergence of converging technologies and, in particular, the technological visions driving this convergence on, also make us realize the extent to which, as yet, our morality has been founded on all sorts of notions of human nature, for example that people aim for happiness and want to avoid pain, or that we are naturally connected to the fate of our fellows, or some of them - or more broadly, with our fellow creatures.

Is the longing for 'naturalness' only a reflex in response to a stimulus? Or are we dealing with expressions of a deeper-lying need that is indeed worth taking seriously? In our opinion, the need for 'naturalness' does not necessarily indicate a longing for a pre-modern, pre-technological age. The contemporary need for naturalness can be better understood as a response to the fact that technology makes reality more and more makeable and, consequently, more contingent. Advancing technology changes everything that is into an object of our choice: it is like this or that, but does it have to be like this or that? We can choose. And that is often fantastic, as we have already said. But what are we supposed to base benchmarks and guidelines on in such a completely conditional, coincidental universe? If human nature itself becomes makeable, it can no longer naively be laid down as the norm. The classical adage of Enlightenment 'Man is the measure of all things' loses all meaning. And if we are no longer able to refer to a given human nature, how do we then determine what we should and should not 'build'? If we could make everything, wouldn't everything become meaningless and wouldn't we end up in a moral vacuum as a result?

\section{Opposition to Perfect Control}

The makeability of life raises opposition and uneasiness for another reason too. Once we can mould nature completely to our will, the relationship we have with it ceases to exist. For example: however much we sometimes wish that our partner fulfilled 
more of our desires, very few people would choose a perfectly-programmable love robot. Recalcitrance is a part of every healthy relationship. We have just as much need of opposition as we have need to overcome it. This need is at the root of our fear of a world without resistance, that may not perhaps entail the risk of sorrow, loss, humiliation and defeat, but no longer has any happiness, gratitude, satisfaction or surprises in store for us either.

The best known example of the aversion aroused by the perfect control of man and world, is that in Aldous Huxley's Brave New World (1932). In this novel, Huxley evokes the image of a world in which everything and everyone is brought under total control. He creates a situation in which everyone has enough to eat and is happy, healthy and always cheerful. And yet, or perhaps because of it, it is a daunting world - although in our liberal culture we no longer have the ethical vocabulary to describe precisely what it is about this picture that is so daunting $[8,13]$. The novel expresses something that cannot be translated in terms of the accepted moral coinage of not-harming, doing good, autonomy and justice. In fact, it confronts us with the metaphysical loneliness of the human who only meets his mirror image everywhere: a world that obediently yields to all our wishes and desires; a world with which a meaningful relationship cannot be concluded because it no longer offers any resistance. If we can make anything and do not have to accept anything, life loses its meaning and beauty. That is the underlying fear that overcomes many of us when we contemplate a world without resistance in which everything, including who we are as humans, has become the object of human intervention.

This need of opposition is a major reason why the discussion on 'natural' and 'unnatural' is constantly resurrected. Many people, for example, prefer to see having children as a natural part of life rather than as a part of a life plan, and want to accept a child with all his or her unexpected characteristics, instead of designing the ideal one. Nature is still the symbol of that over which we have no control, that which overcomes us and to which we have to relate. And the fact that there is a grey zone here (perhaps we will, for example, want to prevent children with severe handicaps from having to live) does not detract from the fundamental experience that many people do not want to be able to control everything [23].

\section{Making and Accepting}

On the basis of the history of technological development, it is to be expected that the logic of building the organic world will not spread without resistance. The fears and considerations described above will certainly play up. Converging technologies create 'boundary conflicts' between the objectifying and social perspectives and appear not to be at all concerned about the taboos monitoring this boundary. This will lead to considerable social unrest and the reaction to converging technologies will, as a result, be much fiercer than one would expect on the basis of the directly perceptible consequences. Policymakers can, at least, prepare for this. The big question will subsequently be how this development can be supervised by society. There are no cut-and-dried answers to this question, even if this special issue does provide a perspective on the importance of the development and provides handles for dealing with the proliferation of the logic of building the organic world and keeping it within bounds.

\section{The Industrial Revolution as Source of Inspiration}

We can derive inspiration and understanding from developments in the past. In the course of time, the industrial revolution entailed countless changes, challenges and problems. It coincided with the emergence of the machine, the city, science, big companies and also, last but not least, democracy. Its birth was accompanied by violent social, economic, ideological and political strife (capitalism, anarchism, Marxism, socialism, etc), which has determined a significant part of our political agenda up to the present day. It was only in the nineteen sixties that the realization finally dawned on a wider audience that this building logic had enormous repercussions for nature: nature was scarce and resources finite. Depletion of the environment threatened to make the pursuit of control over it impossible.

From that point in time, nature conservation became an important political issue, but the problems, from the depletion of fossil fuels to water shortages, soot emissions from diesel trucks and climate change, seem to increase by the day, precisely because we have been so late in realizing the danger. 


\section{Expansion of the Concept of Sustainability}

The first thing this period in history has taught us is that it is better if we can anticipate the drawbacks of the logic implicated in new technology in good time. Otherwise the problems will be much more difficult to fix. The second lesson is more substantive. Comparison with the industrial revolution shows that the information revolution adds a third political dimension to the two mentioned above: besides the struggle between work and capital and the fight for the environment, we now encounter fights at the levels of biopolitics and bioethics (see, for example, [11]). The industrial revolution has resulted in ideals such as economic justice and sustainability being given a prominent place on the political agenda. This raises the question of what ideals can provide a framework when it comes to the technological design of living beings, ourselves included.

If we intuitively recoil from the comprehensive application of the building logic to living beings, we will have to give adequate shape to this question. In the light of the promise of NBIC convergence, 'human nature' is probably too static or too biased (because it is inherently conservative) to function as an ideal [4]. After all, for some, this human nature forms a point of departure rather than a boundary that has to be respected. A framework can therefore be found in joining up with the existing concept of sustainability. Despite, or perhaps because of, the vagueness of this concept, it has led to a productive discourse that has modified the ideals of the industrial revolution and stimulated the discussion on the direction of (sustainable) innovation. It provides a counterbalance for our drive to control, or rather: the concept of sustainability steers and assists the way in which we deal with external nature. Sustainability requires precision and a certain restraint too, because otherwise depletion and even the extinction of our natural resources are lying in wait. Now that we ourselves are increasingly becoming the object of research and technological intervention, we need 'human sustainability' [29].

\section{Making and Accepting}

The essence of a sustainability concept that has been expanded in this way should be formed by joint reflection on the question: what is makeable and what should simply be accepted? Converging technologies will lead to controversies around the currently still accepted dividing line between the objectifying and the social perspectives. The aim of these controversies is ultimately to define what is human and where the boundary between building and influencing should be drawn. Put another way: what should we accept or respect as given, and what may we deem changeable [7]? Human sustainability will not be possible unless we reflect on and deal with the tension evoked by technological progress in general and by converging technologies in particular. It is precisely this dialectic between makeability on the one hand and the need for opposition on the other that, according to the articles in this special issue, crystallizes out around the technological convergences discussed. It is unlikely that it will ever be settled. There is probably little else for us to do than to continue the discussion.

\section{Double Dynamics}

Converging technologies entail a certain double dynamics: destabilization of concepts that serve as a guide, and subsequently their new interpretation in the light of the changed circumstances. The technoscientific developments discussed in this special issue: brain-machine interaction, ambient intelligence and persuasive technology, molecular medicine, and synthetic biology, all show the abovementioned double dynamics: key concepts are retained, but their meaning and practical details are under dispute and can shift. In conclusion, we list those central categorizing concepts that will have to be rediscovered as a result of the various developments and how the discrepancy between 'making' and 'accepting' continues to pervade this discussion (see also Table 1).

\section{Brain-Machine Interaction}

In developments in the field of brain-machine interaction it is the key concepts of body and person that are at issue. One of the questions that have emerged as a result is: what defines a body? The underlying moral question here concerns the degree to which a body deserves protection. Schermer wonders whether we should perhaps see body prostheses, from artificial arms to cochlear implants, as parts of the body. A technologically-inspired symbolic expansion of the concept of body like this would, of course, have 
Table 1 The relationship between emerging technologies and key symbolic concepts

\begin{tabular}{|c|c|c|}
\hline Scientific and technological development & Key symbolic concept & Expansion or reduction of key concept \\
\hline Brain-machine interaction & $\begin{array}{l}\text { Body / physical integrity } \\
\text { Person }\end{array}$ & $\begin{array}{l}\text { Technology as integrated component of the body } \\
\text { Person extends beyond the body (remote control, avatars) } \\
\text { Robot (machine as 'autonomic' actor) }\end{array}$ \\
\hline $\begin{array}{l}\text { Ambient Intelligence / Persuasive } \\
\text { technology }\end{array}$ & Actor & $\begin{array}{l}\text { Machine as responsible actor, or rather, human in interaction } \\
\text { with technology as actor }\end{array}$ \\
\hline Molecular medicine & Healthy or sick & $\begin{array}{l}\text { Illness as a molecular process that may vary for each individual } \\
\text { Non-sick patient }\end{array}$ \\
\hline Synthetic biology & $\begin{array}{l}\text { Living and non-living } \\
\text { Material and } \\
\text { informational } \\
\text { Natural and artificial }\end{array}$ & $\begin{array}{l}\text { Life as an information-processing system (reduction) } \\
\text { Copying life on the basis of a code } \\
\text { New forms of life }\end{array}$ \\
\hline
\end{tabular}

consequences for policy and legislation. Schermer is also of the opinion that there is a need for a graduated or differentiated concept of a 'person'. Developments in the field of the brain sciences and artificial intelligence also require reflection on the concept of person and issues such as liability, responsibility and worthiness of protection. Consider, for example, autonomic robots, avatars and exoskeletons.

The possibility of technology being used to manipulate personality and will lurks in the background here. If we extrapolate the abovementioned makeability in our mind's eye, at the end we see the extreme of a person whose experience and will are determined totally by external factors. We can imagine how these people could be completely happy — in accordance with the (implicit) adage of Brave New World: 'you want what you can have, and what you cannot have you do not want'. Authenticity loses all meaning in this situation; perhaps even the concept 'person' does too. The opposite of this extreme is to embrace human imperfections and shortcomings on the basis of the assumption that our humanity is to be found in the way we deal with these imperfections and shortcomings and give them meaning. Technology itself is, however, one of the most impressive ways of dealing with them - in fact by correcting or compensating for them. There is a lot of human greatness in this pursuit. Only the problem is that, at the same time, we seem to hope that we will ultimately lose the fight because a total victory would negate our humanity. In the case of brain-machine interaction the important thing is therefore to find a new, precarious balance between building and controlling or accepting.
Ambient Intelligence and Persuasive Technology

Ambient intelligence and persuasive technology raise similar questions. The key symbolic concept here is 'actor'. Responsibility and freedom are the important moral issues involved. What we always had to accept as given, was the fact that people do not always do the right thing, because they are bad or because they are weak willed. The idea underlying persuasive technology is that neither has to be accepted any more, but that they can be corrected by technical means. However, the price we have to pay for this is the loss of our humanity. This is why the ideal of human sustainability compels us to rethink the balance between freedom (with all its advantages and disadvantages) and definition or determinability (with all its advantages and disadvantages). That is precisely what Verbeek advocates.

The term 'actor' is usually understood to refer to people: an individual, group or organization that carries out an action. Verbeek indicates that, because of developments in the field of IT, the concept 'actor' should perhaps be expanded with things or machines. He suggests a subtle expansion: that from now on we have to look very consciously at the interaction between man and machine. That applies to designers and policymakers, but also to users. The way in which an individual can still be held responsible can be judged on the specific technological context. In a situation in which technology imposes compulsory behaviour on a certain person, there can be no question of that person being liable. We therefore have to be aware of what we are dealing with in the 
case of intelligent environments. They entail gradations of freedom and responsibility that are somewhat analogous to Schermer's graduated concept of 'person'. Instruments such as 'informed consent' and possibilities for 'opt-outs' may help in clarifying the apportioning of responsibility in certain circumstances and combating abuse. Besides matters concerning privacy, numerous political questions also play a role here, such as where the boundaries lie between public, commercial and private domains.

\section{Molecular Medicine}

Molecular medicine sees the body as a system consisting of components. It is based on the assumption that you can control the body by controlling the separate components and promises us a completely transparent body. According to Boenink, this view undermines existing approaches to the body that entail a non-transparent, organic, holistic whole with its own developmental story that is to be respected. In this case, the objectifying view of the doctor conflicts with the physical experiences of the patient him or herself. According to the one the body can be sick, but according to the other there is no problem as yet. As regards the key concept 'sick', converging technologies force us to re-examine the question of when one is sick and the meaning of illness. The emergence of molecular medicine changes the meaning of being sick. This perspective, particularly if this scientific image becomes successful in practice, generates a different interpretation of the concept: it is no longer primarily connected to visible symptoms of illness but is deemed a phenomenon at the molecular level. Molecular medicine therefore raises the question of whether we must follow different molecular processes and manipulate them where possible, or not.

Molecular medicine uses what are known as biomarkers to signal biochemical changes at the molecular level and, by doing so, diagnose or predict illness in good time. This view of illness (illness as cascade) is also already visible in current trends for predicting and preventing illness early on. This does not alter the fact that it raises numerous questions. How do you deal with the knowledge that, in time, you will develop complaints? How do you deal with the uncertainties that such knowledge often throws up? A new, modified interpretation of the symbolic key concept 'sick' will have to be developed. This could take place in various ways. The concept can, for example, be broadened so that we can use the term 'sick' when it has been ascertained that something is going wrong on the molecular level. But it is also possible that we will differentiate the concept, for example by speaking of a patient being 'symptomatically sick' and 'pre-symptomatically sick'. Finally, the concept can also be restricted in meaning by, for example, reserving it only for cases in which clearlyobservable symptoms occur. The route chosen will, in turn, have consequences for policy and legislation.

As a result of shifts of this kind, the healthcare system can take on radically new characteristics. And in the background there will always be the question of: when do we intervene? On the basis of the human sustainability perspective, where is the boundary between accept and intervene? What applies as natural variation and what as a deviation that is to be remedied? What do we have to live with, or learn to live with, and what should be rectified?

\section{Synthetic Biology}

Finally, synthetic biology raises the question of what life is. Van den Belt indicates that the scientific world increasingly describes life as a self-reproducing, information-processing system. This vision of life has already penetrated into the European patent law, where 'biological material' is defined as 'material that contains genetic information and can replicate itself or can be replicated in a biological system'. Van den Belt calls this 'the computerization of life'. Computerization has already been going on for decades but synthetic biology forms a significant step in that it adds the ideal of 'building' to this development. Seen from this perspective, the organism is a code that can be rewritten, or a machine that can be reprogrammed. The computerization of life not only diminishes the definition of life, but also ensures its expansion at the same time. New forms of life, including artificial ones, lie in store for us. Many of them will have useful applications, but some may not. This throws up a new challenge for the opponents of bioterrorism.

But the reductionistic vision used by scientists clashes regularly with (as yet) accepted visions on life. The perspective of synthetic biology is at odds with that of the acceptance of life as it comes, of being grateful for the arrival of children instead of 
consciously having them for all the wrong reasons, of the cheerful embracing of 'handicapped' life because it is just one of those things, of respect for the sanctity of life. If synthetic biology lives up to expectations, will there still be scope for the fundamental human experience of being surprised by unintended forms of life? And if we are allowed to make bacteria, will we be allowed to do the same with people? And if not, on what grounds would such a prohibition be based if the message of synthetic biology is that organisms are the result of pure coincidence and can therefore be revised and improved? Is the patenting of life ethically responsible or does objectification go too far in this case? Or should we no longer take such respect seriously and deem it a reflex from the era of ignorance of the molecular processes that make the difference between living and non-living matter?

\section{Conclusion}

With this special issue we have attempted to offer a philosophical perspective on the broad emergence of NBIC convergence: the new technological wave. A perspective of this kind is useful in this early phase as it anticipates and draws attention to existing and possible emergent problems.

We have shown that NBIC convergence is founded on a fundamental paradigm shift. As a result of convergence, a form of making that has so far been limited to our interventions in the domain of nonliving nature is expanding into the domain of living nature, ourselves included. Because of this, the fundamental symbolic distinction between non-living matter and living organisms is blurring. Our experience with the negative consequences of industrialization for the environment and familiar dystopias such as those described in Brave New World clearly show that practically no one will benefit from the introduction of this building logic in its entirety.

This is why reflection on the building logic with respect to life and debate on its boundaries are so important. Various authors therefore argue that biopolitical issues will form an increasingly important dimension in the political debate as a result of NBIC convergence $[11,21,28]$. In this way, NBIC convergence forms a potentially 'rich' source of social uneasiness and political points of difference.
To make matters more complex, this reflection also has simultaneously to deal with the modern experience that things are fundamentally out of control. It is an interesting observation that the discourse of 'making nature' is accompanied with a counterdiscourse that states that society is not makeable. In policy literature, to take an example, the idea of a centre governing the rest of society has been substituted by the idea of governance, which is much more akin to 'influencing' and 'compromising with' organisms. Similarly, technology itself is often perceived as unmakeable. And even those who think otherwise, usually will refrain from arguing that we can control technological developments. At most we can exert a certain pressure. Again, this is much closer to 'influencing' than to 'building'.

This special issue touches on numerous existing, emergent and possible future 'ultra-untameable' problems or boundary conflicts. Technology that is gradually taking on the traits normally associated with a (moral) actor, in the form of autonomic robots, artificial life and so on, is challenging policy more and more. Often there is a clash between existing social logic (norms and values and the related conceptual frameworks) and the scientific and technological building logic of converging technologies. These clashes can invoke fierce reactions because building logic often affects taboos connected with contemporary self awareness. Human sustainability appears to be under pressure. At every clash, we will have to examine the extent to which it is desirable and possible to incorporate the new logic into existing practices.

Important symbolic classifications are therefore on the line. The reduction, expansion, gradation and differentiation of important concepts such as body, life, person and illness converge here. Reductionism is the driving force behind much science and technology. Expansion and differentiation are ways to embed scientific developments in social practices. Human values such as freedom, equality, the possibility of taking responsibility, the right not to know and so on are central to that process.

The socialization of scientific findings does not, however, take place automatically. It is precisely because converging technologies unsettle various central symbolic classifications, that it is important that we are aware of what we are dealing with in the case of public investments and the concepts implicated. This 
necessitates the constant involvement of policymakers, politicians and social groups. In order not to become swamped by the new technological wave, the debate on the significance of these developments and the best ways to steer them in the right direction must be continually stimulated.

Open Access This article is distributed under the terms of the Creative Commons Attribution Noncommercial License which permits any noncommercial use, distribution, and reproduction in any medium, provided the original author(s) and source are credited.

\section{References}

1. Arendt H (1958) The Human Condition. The University of Chicago Press, Chicago

2. Borup Mads, Nik Brown, Kornelia Konrad, Harro Van Lente (2006) The sociology of expectations in science and technology. Technol Anal Strateg Manag 18(3/4):285-298

3. Brooks R (2002) The Merger of Flesh and Machines. In: Brockman J (ed) The next fifty years: science in the first half of the twenty-first century. Vintage Books, New York

4. Bostrom N (2005) A history of transhumanist thought. Journal of Evolution and Technology 14(1):1-25

5. Dekker W (2009) De affaire Buikhuisen: het ontstaan en de achtergronden van de rel rondom zijn biosociale onderzoek. Doctoraalscriptie. Erasmus Universiteit, Rotterdam

6. Douglas M (1966) Purity and danger. An Analysis of the Concepts of Pollution and Taboo. Routledge and Kegan Paul, London

7. Dupuy JP (2007) Some pitfalls in the philosophical foundations of nanoethics. J Med Philos 32(3):237

8. Fukuyama F (2002) Our posthuman future. Profile Books

9. Grunwald A (2007) Converging Technologies: visions, increased contingencies of the conditio humana, and search for orientation. Futures 39(4):380-392

10. Habermas J (1981) Theorie des kommunikativen Handelns. Suhrkamp Frankfurt

11. Hughes J (2004) Citizen cyborg: Why democratic societies must respond to the redesigned human of the future. Westview Press, Boulder

12. Kant I., J. Timmermann (2004) Grundlegung zur Metaphysik der Sitten. Vandenhoeck \& Ruprecht

13. Kass, L. R. 2002. Life, liberty, and the defense of dignity: The challenge for bioethics. Encounter books.
14. Kearnes M (2009) Informationalising Matter: Systems Understandings of the Nanoscale. Spontaneous Generations. A Journal for the History and Philosophy of Science 2(1):99

15. Keulartz J, Schermer M, Korthals M, T. Swierstra (2004) Ethics in technological culture: A programmatic proposal for a pragmatist approach. Science, Technology \& Human Values 29 , no. 1:3

16. Maienschein J (2009) Controlling Life: From Jacques Loeb to Regenerative Medicine. J Hist Biol 42:215-230

17. McEuen P, Dekker C (2008) Synthesizing the Future. ACS Chem Biol 3:10-12

18. Merelman RM (2000) "Technological cultures and liberal democracy in the United States", Science. Technology \& Human Values 25(2):167-194

19. Nordmann Alfred (2007) If and Then: A Critique of Speculative NanoEthics. NanoEthics 1, no. 1 (March 7): 31-46. doi:10.1007/s11569-007-0007-6

20. Nordmann Alfred, Arie Rip (2009) Mind the gap revisited. Nat Nano 4, no. 5 (May): 273-274. doi:10.1038/nnano.2009.26

21. The PAGANINI project (2007) Participatory governance and institutional innovation: The new governance of life. Department of Political Science, University of Vienna, A summary report of the PAGANINI project. Austria

22. Roco MC, Bainbridge WS (eds) (2002) Converging Technologies for Improving Human Performance, National Science Foundation. Arlington, VA

23. Sandel M (2007) J. Ethics in the age of genetic engineering. belknap Press, The case against perfection

24. Smit A (2007) "Bouwen aan de blauwprint van het leven". Intermediair 3 October 2007, to be found at www.intermediair. nl/artikel.jsp?id=1010099

25. Smits Martijntje (2006) Taming monsters: The cultural domestication of new technology. Technology in Society 28, no. 4 (November): 489-504. doi:10.1016/j.techsoc.2006.09.008

26. Taylor C (1994) Sources of the self: The making of the modern identity. Harvard University Press

27. Toffler A (1980) The third wave. Bantam Books, New York

28. Van Est R, Enzing C, van Lieshout M, Versleijen A (2006) Welcome to the 21st century: Heaven, hell or down to earth? A historical, public debate and technological perspective on the convergence of nanotechnology, biotechnology, information technology and the cognitive sciences. European Parliament / STOA, Brussels

29. Van Est R, Klaassen P, Schuiff M, Smits M (2008) Future man - No future man: Connecting the technological, cultural and political dots of human enhancement. The Hague, Netherlands Organisation for Scientific Research (NWO)

30. de Vriend H (2006) Constructing Life: early social reflections on the emerging field of synthetic biology. Rathenau Institute, The Hague 